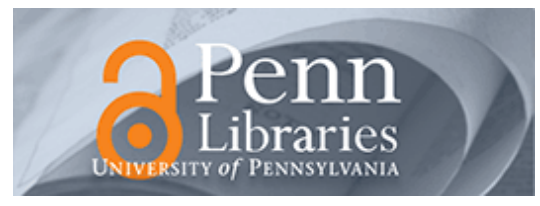

University of Pennsylvania

ScholarlyCommons

Accounting Papers

Wharton Faculty Research

$7-2010$

\title{
Endogenous Selection and Moral Hazard in Compensation Contracts
}

Christopher S. Armstrong

University of Pennsylvania

David F. Larcker

Che-Lin Su

Follow this and additional works at: https://repository.upenn.edu/accounting_papers

Part of the Accounting Commons

\section{Recommended Citation}

Armstrong, C. S., Larcker, D. F., \& Su, C. (2010). Endogenous Selection and Moral Hazard in Compensation Contracts. Operations Research, 58 (4-part-2), 1090-1106. http://dx.doi.org/10.1287/opre.1100.0828

This paper is posted at ScholarlyCommons. https://repository.upenn.edu/accounting_papers/95

For more information, please contact repository@pobox.upenn.edu. 


\title{
Endogenous Selection and Moral Hazard in Compensation Contracts
}

\begin{abstract}
The two major paradigms in the theoretical agency literature are moral hazard (i.e., hidden action) and adverse selection (i.e., hidden information). Prior research typically solves these problems in isolation, as opposed to simultaneously incorporating both adverse selection and moral hazard features. We formulate two complementary generalized principal-agent models that incorporate features observed in real-world contracting environments (e.g., agents with power utility and limited liability, lognormal stock price distributions, and stock options) as mathematical programs with equilibrium constraints (MPEC). We use state-of-the-art numerical algorithms to solve the resulting models. We find that many of the standard results no longer obtain when wealth effects are present. We also develop a new measure of incentives calculated as the change in the agent's certainty equivalent under the optimal contract for a change in action evaluated at the optimal action. This measure facilitates interpretation of the resulting contracts and allows us to compare contracts across different contracting environments.
\end{abstract}

\section{Keywords}

generalized principal-agent model, executive compensation, mathematical programs with equilibrium constraints

Disciplines

Accounting 


\title{
Endogenous Selection and Moral Hazard In Compensation Contracts ${ }^{\dagger}$
}

\author{
Christopher S. Armstrong \\ carms@wharton. upenn. edu \\ The Wharton School \\ University of Pennsylvania \\ 2400 Steinberg-Dietrich Hall \\ Philadelphia, PA 19104-6365 \\ David F. Larcker \\ Larcker_David@gsb.stanford.edu \\ Rock Center for Corporate Governance \\ Stanford University \\ Graduate School of Business \\ 518 Memorial Way \\ Stanford, CA 94305-5015 \\ Che-Lin Su \\ Che-Lin.Su@chicagobooth.edu \\ The University of Chicago \\ Booth School of Business \\ 5807 S. Woodlawn Ave \\ Chicago, IL 60637
}

February 13, 2010

\footnotetext{
${ }^{\dagger}$ We appreciate the helpful comments from Stanley Baiman, Anne Beyer, Kenneth Judd, Sunil Kumar, Richard Lambert, and Madhav Rajan. Che-Lin Su is grateful for financial support from the NSF (award no. SES-0631622) and from The University of Chicago Booth School of Business.
} 


\title{
Endogenous Selection and Moral Hazard In Compensation Contracts
}

\begin{abstract}
The two major paradigms in the theoretical agency literature are moral hazard (i.e., hidden action) and adverse selection (i.e., hidden information). Prior research typically solves these problems in isolation, as opposed to simultaneously incorporating both adverse selection and moral hazard features. We formulate two complementary generalized principalagent models that incorporate features observed in real world contracting environments (e.g., agents with power utility and limited liability, lognormal stock price distributions, and stock options) as mathematical programs with equilibrium constraints (MPEC). We use stateof-the-art numerical algorithms to solve the resulting models. We find that many of the standard results no longer obtain when wealth effects are present. We also develop a new measure of incentives calculated as the change in the agent's certainty equivalent under the optimal contract for a change in action evaluated at the optimal action. This measure facilitates interpretation of the resulting contracts and allows us to compare contracts across different contracting environments.
\end{abstract}

JEL Classification: C60, C61, J33, M52

Keywords: Generalized Principal Agent Model, Adverse Selection, Moral Hazard, Executive Compensation, Mathematical Programs with Equilibrium Constraints 


\section{Endogenous Selection and Moral Hazard In Compensation Contracts}

\section{Introduction}

This paper examines the characteristics of optimal compensation contracts that emerge from generalized principal agent models (Myerson 1982) that feature both adverse selection and moral hazard. Adverse selection (or "hidden information") exists when one of the parties (typically the agent) possesses private information that is relevant for contracting before entering into a contractual arrangement with its counterparty (typically the principal). Moral hazard (or "hidden action") exists when one of the parties (again, typically the agent) takes an action that is unobservable to its contracting counterparty. ${ }^{1}$ The fundamental optimization problem in these types of economic games is for the principal to design an incentive feasible compensation contract that maximizes its expected payoff given the information structure of the game.

A vast theoretical economics literature examines the solution to these types of agency models (see Laffont and Martimort 2002 and Lambert 2001 for useful reviews). One notable feature of this literature, however, is that the two agency problems are typically solved in isolation (i.e., either a moral hazard or an adverse selection setting is examined). ${ }^{2}$ This is

\footnotetext{
${ }^{1}$ An alternative way of describing a moral hazard setting is one in which the agent acquires information relevant to the contractual arrangement after the contract is executed. In this case, the information is typically about the action that the agent took that the principal cannot observe or verify. In the generalized principal-agent model studied in Myerson (1982), the agents either (1) have information that the principal cannot observe and/or (2) have the power to make some decisions that the principal cannot directly control. These scenarios are also referred to as adverse selection and moral hazard, respectively.

${ }^{2}$ In some special settings, there is equivalence between moral hazard and adverse selection models. For example, Milgrom (1987) and Haterty and Siegal (1988) show that the adverse selection and moral hazard models are fundamentally similar and that this modeling choice is largely arbitrary. However, when the agent has limited liability, the transformation from a moral hazard to an adverse selection model is not straightforward.
} 
particularly the case when the agency model relates to (executive) compensation contracts. Despite the focus on one type of model in most of the extant theoretical literature, (Laffont and Martimort 2002, p. 265) note that in real world settings, contracts are rarely designed with the sole objective of solving one incentive problem. Instead, the principal's control of the agent typically requires that the contracts deal simultaneously with both adverse selection and moral hazard. This sentiment is echoed in the stated goals of executive compensation policies at most large U.S. corporations, such as the Ford Motor Company:

"Compensation will be used to attract, retain, and motivate employees and to reward the achievement of business results through the delivery of competitive pay and incentive programs." (2007 proxy statement; emphasis original).

Similarly, survey results clearly highlight the importance of attracting, retaining, and rewarding key employees as the predominant goals of employee compensation practices. One survey by iQuantic (1999) found that the three main objectives of the respondents' stock option programs are to retain key employees (89.7\% of respondents), reward specific project milestones or goals (68.5\%), and attract employees (65.1\%). The survey also found that the objectives of the respondents' restricted stock programs are to retain (71\%), attract $(44.1 \%)$ key employees, and to link individual to company performance (44.0\%). In order to understand compensation practices, it is therefore necessary to analyze models that simultaneously incorporate both adverse selection and moral hazard features.

Even absent adverse selection considerations, the solution to typical moral hazard problems is especially difficult. In particular, the bi-level nature of the resulting optimization problem generally precludes a closed form solution without relying on strong (and often unrealistic) assumptions about the nature of the contracting environment. For example, in order 
to obtain closed form results it is often necessary to restrict the contract space to strictly linear contracts, assume that agent utility functions exhibit constant absolute risk aversion (CARA) where agent wealth is not relevant, and restrict the conditional distribution of the observed output given the agent's action choice (e.g., the agent's action might affect only the mean and not other higher moments of the outcome distribution). ${ }^{3}$

Moreover, moral hazard problems are typically solved by assuming the validity of the "first-order approach," which allows for the agent's incentive compatibility constraints (which represent the agent's, or the "lower level," optimization problem) to be replaced by the firstorder condition for an optimum. Although the resulting "relaxed" version of the problem is more amenable to standard nonlinear optimization techniques, satisfying the sufficient conditions required to invoke the first-order approach (e.g., Rogerson 1985, Jewitt 1988, Araujo and Moreira 2001) often results in highly stylized setups that do not resemble contracting environments observed in practice. As we discuss later, the first-order approach typically fails when realistic contracting features (e.g., nonlinear compensation contracts and non-normal probability distributions) are incorporated in the model. Since closed form mathematical solutions are generally intractable, it is necessary to use sophisticated numerical methods to gain insight into realistic agency problems.

In this paper, we develop and solve a set of agency models that incorporate many features that are observed in real world executive contracting settings. Consistent with considerable prior research in finance and economics, we assume that the firm's stock price is lognormally distributed. This distributional choice allows for the action the agent selects to affect both

\footnotetext{
${ }^{3}$ It is common to assume that compensation contracts are linear, that agents have negative exponential utility functions, and that outcome distributions are conditionally normal, which is referred to as the "LEN framework". While these assumptions may allow closed form solutions to the problems, they ignore important features such as the role of limited liability and agent wealth, common compensation instruments such as stock options (which have a nonlinear payoff), and the empirical observation that stock prices tend to be lognormally distributed. See Hemmer (2004) for a more detailed critique of the LEN modeling framework.
} 
the mean and variance of the stock price distribution and thereby capture the risk-return tradeoff that is at the heart of most managerial decisions.

We also assume that agent utility functions are a member of the power class of functions which exhibit decreasing absolute and constant relative risk aversion (CRRA). This choice is supported by prior empirical work by Friend and Blume (1975) and Litzenberger and Ronn (1986). ${ }^{4}$ We adopt power utility rather than the more common (at least in analytical work) negative exponential (i.e., CARA) utility, because managerial wealth is undoubtedly an important factor for understanding executive incentives. Finally, similar to observed compensation arrangements, the contract space is general enough to allow for a fixed salary, restricted stock, and "at-the-money" stock options and provides limited liability for the agents. $^{5}$

We first consider a traditional moral hazard model in which a principal (e.g., the board of directors acting on behalf of shareholders) hires a risk- and effort-averse agent to take an unobservable (and therefore noncontractible) action that affects the distribution of the firm's stock price. This model provides a benchmark solution for interpreting the results from more complex models and highlights the difficult technical issues that arise when realistic assumptions are incorporated into a fairly standard agency model. We address these difficulties by reformulating the problem as a mathematical program with equilibrium constraints (MPEC) (see Luo et al. 1996) and then solve the resulting problem using state-of-the-art numerical algorithms.

\footnotetext{
${ }^{4}$ Friend and Blume (1975) estimate the risk aversion parameter for the power utility to be between two and three. Kocherlakota (1990) argues that this parameter is probably higher (perhaps in excess of ten), although Lucas (1994) suggests that the parameter should be around 2.5. Consistent with prior research, we consider coefficients of relative risk between two and four in our analysis.

${ }^{5}$ Salary, restricted stock, and at-the-money stock options account for the vast majority of a typical executive's annual remuneration at large, publicly traded companies (e.g., see the discussion in Murphy 1999). In addition, we incorporate limited liability for the agent into our models since this is a prevalent feature of most executive contracting environments.
} 
We next examine two complementary versions of the contracting problem in which both adverse selection and moral hazard considerations confront the principal. The first setting is one in which the principal's objective is to employ every type of agent that applies for employment and, accordingly, the principal offers a menu of contracts from which each agent can select. The contracts are designed to achieve the dual objective of eliciting each agent's "type" (which we specify as the agents' degree of risk-aversion) and subsequently motivating each agent to take the action the principal desires. This model resembles the canonical adverse selection model (e.g., Baron and Myerson 1982) and is relevant to a setting in which the firm is willing to hire multiple types of divisional managers, but is uncertain about the risk aversion (or some other relevant characteristic) of each applicant.

The second setting is one in which the principal's objective is to attract and subsequently motivate only a single agent from the population (of ex ante indistinguishable agents). In this case, the contract must not only attract and motivate the desired type of agent, but must also dissuade every other type of agent from accepting the contract. This formulation is descriptive of hiring a chief executive officer (CEO) or other high-level executive in a situation in which the firm is again uncertain about the personal characteristics of the various applicants and must insist on hiring the correct type. To our knowledge, this type of model has not been examined in prior research.

Our main findings are as follows. First, we find that both restricted stock and stock options are typically part of the optimal compensation contract, especially when agents are less wealthy and less risk-averse and the firm's stock price is less volatile. This finding stands in sharp contrast to a number of recent studies that conclude that stock options are an inefficient compensation mechanism relative to restricted stock (e.g., Meulbroek 2001 and Hall and Murphy 2002) and that stock options should almost never be part of the 
optimal compensation contract (e.g., Dittmann and Maug 2007). There is not necessarily a monotonic relationship between volatility and the use of stock options, however, since their use is often increasing in volatility at first and then decreasing in volatility for higher values. Second, we find that wealth effects have an important effect on the form of the optimal contract and the resulting incentives the contract provides. Many of the standard results derived from models of pure moral hazard absent wealth effects (i.e., with either CARA utility or risk-neutral agents) no longer obtain in the presence of wealth effects on the part of the agent. For example, the standard moral hazard result that the principal's objective is increasing in the risk-tolerance of the agent does not obtain until the agent is endowed with a sufficient level of beginning wealth. This effect can also be seen in the generalized version of the model in which adverse selection is also present. In addition, we find that wealth effects can produce results that are similar to the countervailing incentives noted by Lewis and Sappington (1989), in which the principal will offer rents to less efficient agents to prevent them from mimicking relatively more efficient agents in an adverse selection setting. Third, we find that when the principal wants to hire only a certain type of agent, the problem quickly becomes infeasible when the agents become wealthier, since their marginal utility of consumption becomes more similar. In this case, the principal is unable to design a single contract to attract and motivate one agent but exclude the others. Finally, in order to compare (optimal second-best) compensation contracts across agents (with different degrees of risk aversion) and contracting environments, we develop a new measure of incentives that captures the change in the certainty equivalent of the agent's contractual payoff for a change in action, evaluated at the optimal action. This definition of incentives differs from the one typically adopted in empirical contracting work (e.g., Core and Guay 1999) and highlights the endogenous nature of this construct, which is a manifestation of the principal and agent's joint optimization problem. 
The remainder of the paper is organized as follows. In Section 2 we discuss the relevant prior literature. In Section 3 we develop two alternative models that incorporate both moral hazard and adverse selection. This section also discusses how a pure moral hazard model and a pure adverse selection model emerge as special cases of these two generalized models. In Section 4 we discuss the optimal contracts under the programs developed in the previous section. Here we also alter certain parameters of the contracting environment to derive numerical comparative statics to yield insight into the optimal contracts derived in the benchmark case. We provide concluding remarks and discuss possible extensions of our analysis in Section 5 .

\section{Prior Literature}

There is a vast literature that examines optimal (second-best) compensation contracts in the presence of either adverse selection or moral hazard, but very few studies that simultaneously model both features. Two relatively recent studies that model both adverse selection and moral hazard in compensation contracts are Jullien et al. (2003) and Sung (2005).

The setup in Jullien et al. (2003) features two types of agents with CARA utility who are distinguished by their degree of risk aversion (i.e., low and high) and two possible outcomes (i.e., success and failure). ${ }^{6}$ The agents exert costly effort that shifts the probability of the outcome distribution from failure to success. When agent risk aversion is private information, Jullien et al. (2003) find the intuitive result that more risk-averse agents select contracts with lower-powered incentives (assuming that the Spence-Mirrlees condition is satisfied). They also find that although "more risk-averse agents always face lower-powered

\footnotetext{
${ }^{6}$ Their justification for the CARA utility function is that it "abstracts from wealth effects on risk aversion that would make the analysis much more complicated." (p. 6).
} 
incentives, they may well provide more effort since this reduces the risk that they face. Hence the relationship between the incentives displayed by the optimal contract and the observed probability distribution of outcomes is ambiguous" (p. 2). ${ }^{7}$

Sung (2005) adopts a continuous-time formulation to the combined adverse selection and moral hazard problems to avoid the technical difficulties associated with applying the first-order approach in a discrete-time setting. In this setup, the agent affects both the drift and volatility of the Brownian motion outcome process. Similar to Jullien et al. (2003), Sung assumes that the agent has CARA utility which precludes wealth effects but is analytically tractable. He finds that the optimal menu of contracts consists of linear contracts. The intuition behind this result is that the principal is able to observe (and therefore contract on) only the final output, which implies that the agent's optimal effort level is constant over time and linear contracts provide the appropriate incentives for constant effort. ${ }^{8}$

Although most of the relevant prior research is theoretical in nature, certain empirical studies confirm the importance of modeling both adverse selection and moral hazard. Notable among these is Lazear (2000), who studies a firm that switched its compensation policy from hourly wages to piece-rate. He estimated that the average worker's output increased by nearly $44 \%$ following the change in compensation policy, which he split into two components. He found that "about half of the increase in productivity results from the average worker producing more because of incentive effects" and that the other half resulted from the firm's ability to "hire the most productive workers and possibly from a reduction in quits among the highest output workers." He also found that "most of the increase in ability is a result of selection through the hiring process that occurs after piece rates are adopted." Thus, there

\footnotetext{
${ }^{7}$ Hemenway $(1990,1992)$ identified this effect in an insurance context as "propitious selection."

${ }^{8}$ This result and the accompanying intuition are similar to those in Holmstrom and Milgrom (1987), who also establish the optimality of linear contracts in certain settings.
} 
is empirical evidence to support the notion that both moral hazard and adverse selection are prominent features in real world contracting settings.

\section{Programs}

There are multiple ways to formulate a mixed model of adverse selection and moral hazard. We consider two that we find especially descriptive. In the first case, the principal designs a menu of contracts, one for each type of agent, from which each agent selects, and then each agent optimizes his or her effort choice against the selected contract. This formulation is most similar to traditional adverse selection models (e.g., Baron and Myerson 1982), in which the principal stands ready to contract with every type of agent in the population and designs a menu of contracts for this purpose. In the second case, the principal designs a single contract to both select the desired type of agent (and dissuade all other types of agents from accepting the contract) and induce that agent to undertake the desired action. Since only a single type agent is hired in this case, the principal cannot necessarily subsidize the information rents that are typically paid to "high type" agents by also hiring relatively "low type" agents, as is the case in a standard adverse selection problem. ${ }^{9}$

\subsection{Setup}

We assume that there are $T$ types of agents indexed by $t \in \mathcal{T}=\{1,2, \ldots, T\}$ with $\gamma_{t}$ denoting the proportion of agents of type $t$ in the population. Each agent chooses an action $a$ from

\footnotetext{
${ }^{9}$ Note that in both cases in which the problem is characterized as both adverse selection and moral hazard, we assume there is full commitment on the part of both the principal and the agent. Although it is well known that full commitment is optimal ex ante, allowing for renegotiation following either the agent's revelation of his type or following the agent taking the action can be optimal ex post (e.g., Hermalin and Katz 1991).
} 
a closed interval $A \subseteq \mathbb{R}$. In order to avoid the difficulties associated with the first-order approach (e.g., Mirrlees, 1975, 1999; Rogerson, 1985), we assume that at the beginning of the period, an agent chooses an action $a$ from a finite set of action choices $\mathcal{A}=\left\{a_{1}, \ldots, a_{M}\right\}$. The outcome is uncertain and can be one of $N$ alternatives. Let $\mathcal{P}=\left\{p_{1}, \ldots, p_{N}\right\}$ denote the outcome space, which is the terminal stock price of the firm ordered from lowest to highest. We use $\pi(p \mid a ; t)$ to denote the conditional probability distribution that specifies the stochastic relationship between a chosen action $a \in \mathcal{A}$ and an outcome $p \in \mathcal{P}$ conditional on the agent's type $t$. Thus, the conditional distribution of the stock price is

$$
\pi(p \mid a ; t)=\frac{1}{p \sigma \sqrt{2 \pi}} \exp \left\{-\frac{(\log p-\mu)^{2}}{2 \sigma^{2}}\right\}
$$

where $\mu=f(a, t)$ so that the agent's action (and potentially his or her type) will affect both the mean and variance (given by $\exp \left\{\mu+\sigma^{2} / 2\right\}$ and $\left[\exp \left\{\sigma^{2}\right\}-1\right] \cdot \exp \left\{2 \mu+\sigma^{2}\right\}$, respectively) of the lognormal price distribution. Finally, we require $\pi(p \mid a ; t)$ to satisfy the full support assumption (i.e., $\pi(p \mid a ; t)>0$ for all $p$ and $a$ for every $t$ ) in order to prevent certain outcomes from perfectly revealing an agent's type.

Without loss of generality, we normalize the number of the firm's outstanding shares to one. The contract space consists of salary, restricted stock, and stock options (with an exercise price $K_{t}$ ) which are denoted $\alpha_{t}, \beta_{1 t}$, and $\beta_{2 t}$, respectively, where the $t$ indexes the contract parameters for agent type. We let $x_{t}=\left(\alpha_{t}, \beta_{1 t}, \beta_{2 t}, K_{t}\right)$ be the contract for the agent of type $t$. For a contract $x_{t}$ and a terminal stock price $p$, the monetary payoff $s\left(x_{t}, p\right)=\alpha_{t}+\beta_{1 t}+\beta_{2 t} \max \left\{p-K_{t}, 0\right\}$. Let $U(\cdot, t)$ and $C(\cdot, t)$ denote agent $t$ 's utility of consumption and disutility of effort, respectively. As is standard in the literature, we assume $U$ to be concave increasing and $C$ to be convex increasing which captures declining marginal utility of consumption and increasing marginal disutility of effort, respectively. In particular, 
each agent has power utility given by $U(W+s)=\frac{1}{1-\delta}(W+s)^{1-\delta}$ for $\delta>0$, where $\delta$ is the coefficient of relative risk aversion, $W$ is the agent's pre-existing wealth, and $s$ is the payoff from the compensation contract. To simplify the notation, we denote agent $t$ 's expected utility of consumption for a given action $a$ as

$$
\left.\mathcal{U}\left(x_{t}, a, t\right)=\mathbb{E}_{p}\left[U\left(s\left(x_{t}, p\right) ; t\right) \mid a\right]:=\sum_{i=1}^{N} \pi\left(p_{i} \mid a ; t\right) U\left(\alpha_{t}+\beta_{1 t}+\beta_{2 t} \max \left\{p_{i}-K_{t}, 0\right\} ; t\right)\right)
$$

where the expectation is taken over the stochastic outcome $p$.

\subsection{A Model of Moral Hazard and Adverse Selection with a Menu of Contracts}

The first mixed model of adverse selection and moral hazard that we consider is one in which the principal offers a menu of contracts (one for each type) that is designed to both induce truthful reporting by each agent (about their type) and motivate each agent to take the desired action for that type. This problem is similar to the classic adverse selection models (e.g., Baron and Myerson 1982) in that the solution is characterized by a menu of contracts from which each agent selects and then takes the action that will yield him or her the highest expected utility under the chosen contract. As long as the menu of contracts consists of a unique contract that each type of agent prefers (i.e., no pooling), an agent's choice of contracts reveals his or her type to the principal. However, unlike with a pure adverse selection model, the principal's problem also involves motivating the agent to take a certain action, which is both unobservable and unverifiable, after the contract is selected. Since the principal cannot discriminate and must hire any agent who seeks employment, this model is perhaps more descriptive of the labor market for lower-level (i.e., non-executive) 
employees. ${ }^{10}$

The formulation of our first mixed model is

$$
\begin{aligned}
\underset{\left\{x_{t}=\left(\alpha_{t}, \beta_{1 t}, \beta_{2 t}, K_{t}\right), a_{t}\right\}_{t \in \mathcal{T}}}{\operatorname{maximize}} & \sum_{t=1}^{T} \gamma_{t}\left[\mathbb{E}_{p}\left(p \mid a_{t}\right)-\mathcal{U}\left(x_{t}, a_{t}, t\right)\right] \\
\text { subject to } & \\
(I R) \forall t \in \mathcal{T}: & \mathcal{U}\left(x_{t}, a_{t}, t\right)-C\left(a_{t} ; t\right) \geq \underline{U}(t) \\
(A S) \forall t^{\prime}(\neq t) \in \mathcal{T}: & \mathcal{U}\left(x_{t}, a_{t}, t\right)-C\left(a_{t} ; t\right) \geq \mathcal{U}\left(x_{t^{\prime}}, a, t\right)-C(a ; t), \forall a \in \mathcal{A} \\
(M H) \forall t \in \mathcal{T}: & a_{t} \in \underset{a \in \mathcal{A}}{\operatorname{argmax}}\left\{\mathcal{U}\left(x_{t}, a, t\right)-C(a ; t)\right\} \\
\forall t \in \mathcal{T}: & \alpha_{t} \geq 0, \quad \beta_{1 t} \geq 0, \quad \beta_{2 t} \geq 0 \quad \beta_{1 t}+\beta_{2 t} \leq 1 .
\end{aligned}
$$

Given the compensation contract $x_{t}=\left(\alpha_{t}, \beta_{1 t}, \beta_{2 t}, K_{t}\right)$ for an agent of type $t$, the moral hazard $(\mathrm{MH})$ constraints in this program induce an agent to take the optimal action for his or her type, $a_{t}$. The individual rationality (or participation) constraints (IR) ensure that the compensation contract satisfies each agent's reservation utility in expectation, conditional on an agent taking the optimal action. ${ }^{11}$ The adverse selection constraints (AS) ensure that an agent of type $t$ will receive higher expected utility if he or she chooses the contract and optimal action specifically designed for his or her type, rather than deviating and selecting a contract designed for a different type of agent and taking any possible action. The final set of contraints implies that the agent receives a non-negative salary, stock, and stock options

\footnotetext{
${ }^{10}$ This model can also be recast as a model of insurance in which the principal is the insurance company and the agents are the insurees that are distinguished by their riskiness. The principal designs a menu of contracts such that each type of agent will select the appropriate contract and then take the desired action. Since insurance providers typically are not allowed to discriminate coverage ex ante, they have to deal with every type of agent in the population and therefore design a menu of contracts to accomplish this task.

${ }^{11}$ It should be noted that the IR constraints as formulated are ex interim IR constraints, since each agent knows his or her type before contracting with the principal. Therefore, the IR constraints must be satisfied in expectation.
} 
and that the agent does not collectively receive more shares and options than there are total shares outstanding (i.e., one).

Note that the first mixed model formulated above is a mixed-integer nonlinear program because of the finite action choices of the agents. In general, mixed-integer nonlinear programs are computationally challenging both because of their combinatorial nature that restricts certain variables to take integer values and because of the nonlinear nature of either the objective and/or constraints. To facilitate the numerical solution of the above problem, we follow Su and Judd (2007) by introducing mixed strategies for the finite action choices to reformulate the program as a mathematical program with equilibrium constraints (see Luo et al. 1996 and the references therein). The main idea is as follows. For $i=1, \ldots, M$, let $\delta_{i}$ denote the probability that the agent will chose action $a_{i}$. Then, given $x_{t}$ and $K_{t}$, an agent of type $t$ chooses a mixed-strategy profile $\delta_{t}^{*}=\left(\delta_{t 1}^{*}, \ldots, \delta_{t M}^{*}\right) \in \mathbb{R}^{M}$ such that

$$
\delta_{t}^{*} \in \underset{e_{t}^{\mathrm{T}} \delta_{t}=1, \delta_{t} \geq 0}{\operatorname{argmax}}\left\{\sum_{k=1}^{M} \delta_{t k} \mathcal{U}\left(x_{t}, a_{k}, t\right)-C\left(a_{k} ; t\right)\right\}
$$

Observe that the agent's mixed-strategy problem above is a linear program and thus its optimality conditions are both necessary and sufficient. By replacing the moral hazard incentive compatibility constraints for finite actions with the optimality conditions for the 
mixed strategy of actions, we derive the following MPEC labeled as Program (\#1):

$$
\begin{aligned}
& \underset{\left\{x_{t}=\left(\alpha_{t}, \beta_{1 t}, \beta_{2 t}, K_{t}\right), \delta_{t}\right\}_{t \in \mathcal{T}}}{\operatorname{maximize}} \sum_{t=1}^{T} \gamma_{t}\left[\sum_{i=1}^{M} \delta_{t i}\left(\mathbb{E}_{p}\left(p \mid a_{i}\right)-\mathcal{U}\left(x_{t}, a_{i}, t\right)\right)\right] \\
& \text { subject to } \\
&(I R) \forall t \in \mathcal{T}: \sum_{i=1}^{M} \delta_{t i}\left(\mathcal{U}\left(x_{t}, a_{i}, t\right)-C\left(a_{i} ; t\right)\right) \geq \underline{U}(t) \\
&(A S) \forall t^{\prime}(\neq t) \in \mathcal{T}: \quad \sum_{i=1}^{M} \delta_{t i}\left(\mathcal{U}\left(x_{t}, a_{i}, t\right)-C\left(a_{i} ; t\right)\right) \geq \mathcal{U}\left(x_{t^{\prime}}, a, t\right)-C(a ; t), \forall a \in \mathcal{A} \\
&(M H) \forall t \in \mathcal{T}: 0 \leq \delta_{t j} \perp\left\{\sum_{i=1}^{M} \delta_{t i}\left(\mathcal{U}\left(x_{t}, a_{i}, t\right)-C\left(a_{i} ; t\right)\right)-\left(\mathcal{U}\left(x_{t}, a_{j}, t\right)-C\left(a_{j} ; t\right)\right)\right\} \geq 0, \forall j \\
& \forall t \in \mathcal{T}: \quad \alpha_{t} \geq 0, \quad \beta_{1 t} \geq 0, \quad \beta_{2 t} \geq 0 \quad \beta_{1 t}+\beta_{2 t} \leq 1, \quad \sum_{i=1}^{M} \delta_{t i}=1 .
\end{aligned}
$$

\subsection{A Model of Adverse Selection and Moral Hazard with a Single Contract}

The second mixed model of adverse selection and moral hazard that we consider is the case in which the principal offers a single contract to induce one agent of a certain type to both select the contract and undertake the desired action once the contract has been selected. For each type $t$, the principal solves the following program to attract and motivate that particular type of agent while also dissuading all the other types of agents from accepting 
the contract.

$$
\begin{aligned}
\underset{\left\{x_{t}=\left(\alpha_{t}, \beta_{1 t}, \beta_{2 t}, K_{t}\right), a_{t}\right\}}{\operatorname{maximize}} & \mathbb{E}_{p}\left(p \mid a_{t}\right)-\mathcal{U}\left(x_{t}, a_{t}, t\right) \\
\text { subject to } & \\
(I R): \quad & \mathcal{U}\left(x_{t}, a_{t}, t\right)-C\left(a_{t} ; t\right) \geq \underline{U}(t) \\
\left(I R^{\prime}\right) \forall t^{\prime}(\neq t) \in \mathcal{T}: \quad & \mathcal{U}\left(x_{t}, a, t^{\prime}\right)-C\left(a ; t^{\prime}\right) \leq \underline{U}\left(t^{\prime}\right), \forall a \in \mathcal{A} \\
(M H): & a_{t} \in \underset{a \in \mathcal{A}}{\operatorname{argmax}}\left\{\mathcal{U}\left(x_{t}, a, t\right)-C(a ; t)\right\} \\
& \alpha_{t} \geq 0, \quad \beta_{1 t} \geq 0, \quad \beta_{2 t} \geq 0 \quad \beta_{1 t}+\beta_{2 t} \leq 1 .
\end{aligned}
$$

The (IR) and (MH) constraints are similar to those in the first mixed model in Section 3.2 and ensure that the compensation contract satisfies the agent's reservation utility in expectation, conditional on the agent taking the optimal action and that an agent of type $t$ takes the desired action for an agent of his or her type, respectively. The (IR) constraints are "non-participation" constraints in the sense that they ensure that agents other than those of the desired type $t$ will not have their reservation utility met for any possible action under the contract. This ensures that agents of a type other than $t$ will never accept the contract designed for an agent of type $t$. Again, there is also limited liability for the agents (i.e., non-negative salary, stock, and stock options, respectively), and the agents cannot receive more shares and options than there are shares of the firm.

Using the same reformulation technique described above, we obtain the following MPEC, la- 
beled as Program (\#2-t), where $t$ denotes the type of agent for whom the contract is designed.

$$
\underset{\left\{x_{t}=\left(\alpha_{t}, \beta_{1 t}, \beta_{2 t}, K_{t}\right), \delta_{t}\right\}}{\operatorname{maximize}} \sum_{i=1}^{M} \delta_{t i}\left(\mathbb{E}_{p}\left(p \mid a_{i}\right)-\mathcal{U}\left(x_{t}, a_{i}, t\right)\right)
$$

subject to

$$
\begin{aligned}
(I R): \quad & \sum_{i=1}^{M} \delta_{t i}\left(\mathcal{U}\left(x_{t}, a_{i}, t\right)-C\left(a_{i} ; t\right)\right) \geq \underline{U}(t) \\
\left(I R^{\prime}\right): \forall t^{\prime}(\neq t) \in \mathcal{T}: \quad & \mathcal{U}\left(x_{t}, a, t^{\prime}\right)-C\left(a ; t^{\prime}\right) \leq \underline{U}\left(t^{\prime}\right), \forall a \in \mathcal{A} \\
(M H) \forall j: \quad & 0 \leq \delta_{t j} \perp\left\{\sum_{i=1}^{M} \delta_{t i}\left(\mathcal{U}\left(x_{t}, a_{i}, t\right)-C\left(a_{i} ; t\right)\right)-\left(\mathcal{U}\left(x_{t}, a_{j}, t\right)-C\left(a_{j} ; t\right)\right)\right\} \geq 0 \\
& \alpha_{t} \geq 0, \quad \beta_{1 t} \geq 0, \quad \beta_{2 t} \geq 0 \quad \beta_{1 t}+\beta_{2 t} \leq 1, \quad \sum_{i=1}^{M} \delta_{t i}=1 .
\end{aligned}
$$

We denote by $\left(x_{t}^{*}, \delta_{t}^{*}\right)$ and $P\left(\left(x_{t}^{*}, \delta_{t}^{*}\right) ; t\right)$ a solution and the optimal objective value to Program $(\# 2-t)$, respectively.

The principal solves Program (\#2-t) for each type $t$ as if type $t$ were to be hired. Then the principal selects the one that yields the highest expected payoff. We summarize this two-step process, labeled as Program (\#2), as follows:

(i) For each type $t$, solve Program $(\# 2-t)$ for $\left(x_{t}^{*}, \delta_{t}^{*}\right)$ and $P\left(\left(x_{t}^{*} \delta_{t}^{*}\right) ; t\right)$.

(ii) Choose the right agent: $\max _{t \in \mathcal{T}} P\left(\left(x_{t}^{*}, \delta_{t}^{*}\right) ; t\right)$.

\subsection{Pure Moral Hazard and Pure Adverse Selection}

Finally, we also solve models of pure moral hazard and pure adverse selection that serve as benchmarks against which to compare the optimal contracts that emerge from Programs (\#1) and (\#2). The results of these models allow us to quantify the efficiency loss that results

from the addition of either adverse selection or moral hazard to the principal's contracting 
problem. For an agent of type $t$, the pure moral hazard program can be viewed as a special case of Program (\#2-t) with the nonparticipation (IR') constraints relating to all of the other types of agents removed. In this case, the principal knows the agent is of type $t$ and must design the contract only to motivate the agent to take the optimal (second-best) action. Pure adverse selection arises as a special case of Program (\#1) with the (MH) constraints removed. In this case, the principal decides each agent's action in the absence of moral hazard and the agents' choice of contracts reveals their types.

\subsection{Solution Approach}

Adverse selection problems are usually solved by invoking the revelation principle, which states that for any general contract and its associated Bayesian Nash Equilibrium, there exists a direct revelation mechanism such that the associated truthful Bayesian Nash Equilibrium generates the same equilibrium outcome. ${ }^{12}$ This implies that it is sufficient to confine the search for an optimal contract to the optimal direct revelation mechanism. In the context of mixed models of adverse selection and moral hazard, there is an analogous "extended revelation principle" (Laffont and Martimort 2002), which says that in addition to the agent sending a message to the principal about his type, the principal also requires that each agent choose a certain action. ${ }^{13}$ Invoking the extended revelation principle allows us to restrict our attention to direct truth-telling mechanisms (alternatively referred to as direct revelation mechanisms in the mechanism design literature) for both mixed models (i.e., Programs (\#1)

\footnotetext{
${ }^{12}$ The revelation principle is usually attributed to Myerson (1979), Green and Laffont (1977), Dasgupta et al. (1979), and Harris and Raviv (1979).

${ }^{13}$ Myerson (1982) develops the extended revelation principle. (Laffont and Martimort 2002, p. 276) also note that the difficulty in modeling adverse selection coupled with moral hazard comes from the fact that the IC constraints may not be as easily ordered as those of a pure adverse selection model. The resulting indirect utility function can fail to satisfy the Spence-Mirrlees property, even in highly structured settings, and such problems can therefore become extremely difficult to solve.
} 
and $(\# 2))$.

We solve the resulting MPEC programs using the SNOPT and KNITRO solvers in AMPL. The use of multiple solvers allows us to compare optimal solutions that emerge from the various programs. In addition, for each program we use 100 multistarts that are equally spaced over the action and contract surface to help ensure that a global solution has been attained.

\section{Optimal Contracts under Adverse Selection and Moral Hazard}

We now discuss the optimal contracts that emerge from the four programs developed in the previous section under a variety of alternative contracting environments. The features that we alter in our numerical analysis are the $\sigma$ parameter of the lognormal price distribution (which roughly corresponds to stock price volatility) and the agent's initial endowment of wealth. We choose these two parameters because one of the primary agency problems when hiring a CEO or other high-level executive is ensuring that their risk-tolerance is compatible with firm's objective of undertaking risky, positive net-present value projects that are appropriate for the firm's risk profile. The volatility of the firm's stock price and an agent's pre-existing wealth both have a first-order effect on an agent's degree of absolute risk aversion and are thus expected to play an important role in the specified contracting environment. We restrict the type space to three agents that differ according to their degree of relative risk aversion which is either 2,3 , or $4 .{ }^{14}$ Each agent has reservation utility of -0.750 , which

\footnotetext{
${ }^{14}$ Although a type space consisting of two agents would result in a more parsimonious setting, we allow for three types because prior authors (e.g., Laffont and Martimort 2002) have noted that in mixed models of adverse selection and moral hazard, the IC constraints may not be easily ordered as a result of the failure of
} 
represents the agent's (non-stochastic) opportunity cost of working for the firm. ${ }^{15}$ Each agent can take one of 11 actions that are uniformly distributed over the (closed) interval $[0,1]$, and the productivity parameter $\phi=1 / 2$ maps an agent's action into the $\mu$ parameter of the lognormal stock price distribution according to the concave (increasing) production technology $\mu=a^{\phi}$. The firm's beginning stock price is arbitrarily set at 50 , and the terminal stock price is conditionally (on the agent's action) lognormally distributed. Consistent with nearly every executive stock option grant at large, U.S. companies, we restrict the exercise price of the options for each agent type $t, K_{t}$, to be at-the-money (or equal to the beginning stock price so that $K_{t}=50$ ). Finally, without loss of generality, we normalize the number of shares outstanding to one so the shares of stock and stock options reported for the various contracts can be interpreted as the fraction of the firm's shares and options on the firm's shares outstanding that are granted to the agent.

We consider nine contracting environments that are characterized by three possible values of sigma and three initial endowments for the agents. Each of the nine possible permutations is presented in Tables 1 through 9 .

the Spence-Mirrlees property to hold. Such failure can result in the "bunching" of agent types on the same contract. Three types is the minimum number of agents required to observe this effect.

${ }^{15}$ One natural extension of this model would be to allow for type-dependent reservation utility. This extension would potentially allow for "countervailing incentives" of the type described by Lewis and Sappington (1989) to arise. In their case, since the most efficient agent has a more attractive outside offer, the principal must provide this type of agent with a relatively high payoff. However, the contract intended for the efficient type then becomes relatively more attractive to inefficient type, which requires the principal to distort upwards the output required from the inefficient agent and, in some cases, also supply this agent with rents. As discussed below, we identify a similar effect when contracting occurs in the presence of adverse selection as a result of wealth effects inherent in the agents' utility functions (rather than type-dependent reservation utility), and the principal offers the less efficient type of agents information rents to prevent those agents from mimicking the more efficient type. 


\subsection{Base Results (Table 1)}

Table 1 presents the base set of results for the moral hazard only and adverse selection only

problems and Programs $(\# 1)$ and $(\# 2)$. The contracting environment in this initial setting can be characterized, relative to the subsequent settings that we consider, as one that has a relatively less volatile stock price $(\sigma=0.50)$ and in which agents are relatively poor (i.e., no initial endowment). In the case of moral hazard only, the principal knows each agent's type and therefore, when contracting with a particular agent, must design the contract only to induce the agent to take the optimal (second-best) action. In this case, we find that the principal's expected payoff (i.e., the value of the objective) is monotonically increasing in the agent's degree of risk aversion (type) so that the principal's objective is highest when dealing with the most risk-averse agent (i.e., coefficient of risk aversion of four). In all three cases, the agents' IR constraints bind, implying that none of the agents earn rents in expectation.

When contracting with an agent with a risk aversion coefficient equal to four, the principal will offer the contract characterized by the $\{$ salary, stock, and stock options $\}$ triplet $\{0.000,0.012,0.017\}$, which will induce the agent to take action 0.7 . This contract implies that the agent is paid a salary of zero, $1.2 \%$ of the firm as shares of stock, and at-the-money options on $1.7 \%$ of the firm's shares. As the coefficient of risk aversion decreases to three, the principal will offer a relatively more convex contract $\{0.000,0.009,0.095\}$, which consists of no salary and fewer shares but substantially more options (i.e., options on $9.5 \%$ of the firm's shares), and the contract will induce the agent to take an action of 0.7. Finally, for the most risk-tolerant agent with a coefficient of risk aversion of two, the principal will offer an even more convex contract $\{0.000,0.010,0.105\}$, which will induce the agent to take an action of 0.6 . 
In order to compare the compensation contracts across varying levels of agent risk aversion and to quantify the incentives provided by the contracts, we compute the change in the agent's certainty equivalent for a small change in the agent's action around the optimal action induced by the contract. Specifically, we calculate incentives as

$$
\left.\frac{\partial C E}{\partial a}\right|_{a=a *}=\frac{C E\left(a^{*}+\epsilon\right)-C E\left(a^{*}-\epsilon\right)}{2 \epsilon}
$$

where $C E(a)$ is the certainty equivalent of the expected payoff from the optimal contract when taking action $a$ and $\epsilon$ is a small value. The change in the certainty equivalent at the optimal action represents the incentives provided by the optimal contract, conditional on the agent taking the optimal action. ${ }^{16}$ The use of the certainty equivalent allows us to compare incentives across utility functions, since differences in the agents' coefficient of relative risk aversion preclude a meaningful comparison of differences in expected payoff.

For the case of moral hazard only, we find that the incentives provided by the optimal contract (conditional on the agent taking the optimal action) are decreasing in agent risk aversion. This result obtains because the agents with a lower coefficient of relative risk aversion are better able to bear the risk that accompanies increased incentives. Since the principal is risk-neutral, it might seem counterintuitive that hiring the most risk-averse agent results in the highest value of the principal's objective and that the optimal contract for this agent induces the highest action of the three types of agents. Recall, however, that the agents have power utility which exhibits wealth effects. Since the agents are not endowed with beginning wealth in the contracting environment described by Table 1, their

\footnotetext{
${ }^{16}$ Note that this measure of incentives in our setting is necessarily an approximation because of the discrete nature of the action space. Nevertheless, this measure reflects the equilibrium nature of incentives and is therefore preferable to alternative measures based simply on the composition of the contract without regard to any attributes of the agent (e.g., risk aversion and wealth). This measure also has the benefit of allowing us to collapse the compensation and action vector to a single scalar amount that can be compared across agents and contracting environments.
} 
consumption consists entirely of the proceeds from their respective contracts. Thus, in the presence of wealth effects, it is possible that agents with higher risk aversion take a higher action but, at the same time, have lower incentives. ${ }^{17}$ This result is clearly observed in the inverse relation between incentives and agent risk aversion.

The results of the adverse selection only model in Table 1 show the optimal contracts when the principal offers a menu of contracts from which each type selects. Compared to the case of moral hazard only, the contracts induce the agents to take higher actions for the least and most risk-averse agents and the same action for the agent with an intermediate degree of risk aversion. Both the composition of the contracts and the incentives provided by the contracts are different from their counterparts in the case of pure moral hazard. The IR constraints for the most and least risk-averse agents bind while the agent with an intermediate degree of risk aversion earns information rents. This result is different from the standard adverse selection result, since information rents are non-monotonic. ${ }^{18}$ This result, similar to the countervailing incentives documented by Lewis and Sappington (1989), obtains in part from the wealth effects that are inherent in the agents' utility functions, which make it desirable for the principal to hire the most risk-averse agent when the agents are not endowed with beginning wealth. To separate the intermediate-type agent from the others, the principal must offer these agents a contract that provides information rents. ${ }^{19}$

\footnotetext{
${ }^{17}$ In order to confirm this intuition, we can look ahead to Table 7 , where we solve for the optimal contract under the same setting, except that each agent is endowed with beginning wealth of 1.0. In this case, we find that it is indeed preferable for the principal to contract with the least risk-averse agent. The optimal contracts for the three agents are $\{0.000,0.002,0.013\},\{0.000,0.000,0.005\},\{0.000,0.000,0.007\}$ for agents with risk aversion coefficients of two, three, and four, respectively. These contracts induce actions of $0.3,0.2$, and 0.2 and yield expected utility for the agents of $-0.750,-0.429$, and -0.255 . The value of the principal's objective when dealing with these three agents is $85.02,77.60$, and 77.54 , respectively.

${ }^{18}$ The standard result in the adverse selection literature (e.g., Baron and Myerson 1982) is that the IR constraint of the "lowest" type binds while all other agents earn information rents that are increasing in their type.

${ }^{19}$ The intuition underlying this effect can be seen most clearly by comparing the optimal contract offered to the most risk-averse agent (i.e., coefficient of risk aversion of four) across moral hazard only and Programs (\#1) and \# 2 in Table 1. The contract offered in the case of moral hazard only is identical to the contract offered in Program (\#1) which implies that when the agents' types are unknown (as is the case in Program
} 
The results for Program (\#1), where the principal offers a menu of contracts, are presented in the third set of columns of Table 1. In this setting, the principal offers three contracts $\{0.000,0.010,0.105\},\{0.000,0.012,0.022\},\{0.000,0.012,0.017\}$, which agents with coefficients of risk aversion of two, three, and four, respectively, will accept. The contracts will induce the agents to take action $0.6,0.6$, and 0.7 , and they will receive expected utility of $-0.750,-0.673,-0.750$, respectively. In addition, the incentives each contract provides are decreasing in the agents' degree of risk aversion (2.902, 0.994, and 0.682, respectively). This result is consistent with the intuition that it is costly for the principal to provide high incentives to more risk-averse agents.

Since the adverse selection only model is a special case of Program (\#1) with the MH constraints removed (so that the principal selects each agent's action rather than allow each agent to select his or her action), we can use the adverse selection only model as a benchmark against which to evaluate the efficiency loss that results from introducing moral hazard on top of the principal's adverse selection problem. In the contracting environment of Table 1 , we find that the agents take uniformly lower actions under Program (\#1), which results in a lower objective for the principal. In particular, the difference in the principal's objective value between the two programs (i.e., 108.51 vs. 101.78) quantifies the economic loss that results from the introduction of moral hazard on top of adverse selection.

(\#1)), the principal will still offer the optimal moral hazard only for the most risk-averse agent as part of the menu in Program (\#1), and those agents will select those contracts. However, this contract is not offered in Program (\#2), where the principal is restricted to offering only a single contract. This implies that if the principal were to offer this contract under Program (\#2), other agents (i.e., those with a coefficient of risk aversion of 2 and/or 3) would still accept this contract but would not take the desired action (of 6). Unlike Program (\#1), where the principal can offer a separate contract for each type of agent, in Program (\#2), the principal is constrained to offer only a single contract and therefore has fewer degrees of freedom to separate the agents. Therefore, in Program (\#1), the principal will design a contract that only the agent with an intermediate degree of risk aversion will select by providing rents to that type of agent. The cost of the rents to the principal is less than the benefit of continuing to offer the optimal moral hazard only contract to the most risk-averse agent in Program (\#1). The same effect is present in the case of adverse selection only, in that to induce the most risk-averse agent to take a high action, the principal is willing to offer a contract to agents with an intermediate degree of risk aversion to preclude them from mimicking the most risk-averse agent. 
The results in the final set of columns of Table 1 characterize the solution to Program (\#2). In this contracting setting, the optimal contract is $\{0.000,0.009,0.095\}$, which the intermediate-type agent will accept and which will induce the agent to take action 0.7. The agent's reservation utility will be exactly satisfied in expectation by the contract, which indicates that there are no information rents associated with this contract. It is worth noting that this contract is identical to the one offered to that type of agent in the case of pure moral hazard, although the principal would prefer to contract with the most riskaverse agent when confronted with only moral hazard. Thus, in the pure moral hazard case, neither the more nor the less risk-averse agent would have accepted the contract designed for the intermediate-type agent, since the contract would not have satisfied the IR constraints of those types of agents. Similarly, the contract that yielded the highest expected utility for the principal under pure moral hazard (i.e., the contract offered to the most risk-averse agent) is not offered under Program (\#2). As discussed in footnote 19, this result implies that one or perhaps both of the less risk-averse agents would prefer this contract in the moral hazard only case but would not take the action the principal desired. This illustrates how the principal's problem becomes more complicated than the case of pure moral hazard when faced with the additional unobservability of agent types as in Program (\#2). It also illustrates how, although both Programs (\#1) and (\#2) both involve adverse selection and moral hazard, Program (\#2) is fundamentally more difficult, because the principal has few instruments (i.e., one contract versus three) with which to screen and subsequently motivate an agent.

Unlike Program (\#1), in which the principal stands ready to hire every type of agent, the principal hires only a single specific agent in Program (\#2), which makes it directly comparable to the pure moral hazard case. The value of the principal's objective under the optimal contract for Program (\#2) is 104.59. If, however, the principal knew every agent's 
type, the principal would instead hire an agent with a coefficient of risk aversion of four, and the optimal contract would also induce the agent to take an action of 0.7 , but it would be cheaper to implement and would result in an objective value of 109.12. The difference in expected returns in this case is $4.53(=109.12-104.59)$ and constitutes an agency cost from the principal's not knowing the agents' types (i.e., the adverse selection problem).$^{20}$

\subsection{Comparative Statics}

We next present a series of numerical comparative statics to provide insight into how the optimal compensation contracts change as a function of certain parameters of the contracting environment. As discussed above, we focus on stock price volatility and the initial endowment of the agent while all of the other parameters (i.e., the agents' productivity, reservation utility, and degree of risk aversion) remain constant throughout the analysis. The table below indicates how stock price volatility and agent endowment vary across tables.

\begin{tabular}{|cc|ccc|}
\hline & & \multicolumn{3}{|c|}{ Initial Endowment (Wealth) } \\
& & 0.00 & 0.50 & 1.00 \\
\hline \multirow{2}{*}{$\sigma$} & 0.50 & Table 1 & Table 4 & Table 7 \\
& 0.75 & Table 2 & Table 5 & Table 8 \\
& 1.00 & Table 3 & Table 6 & Table 9 \\
\hline
\end{tabular}

\footnotetext{
${ }^{20}$ Note that for Program (\#2), it is also possible for the principal to design a contract to exclusively employ either of the other types of agents, even though it is not optimal. If, for example, the principal wanted to hire an agent with a coefficient of relative risk aversion of two, the principal would offer the contract $\{0.000,0.009,0.137\}$, that an agent of this type would select and the other two agents would not, because the contract would not satisfy their reservation utility. Although this contract is similar to the contract offered to this type of agent in the case of moral hazard only, the fact that it is different indicates that at least one of the other types of agents would prefer this contract (rather than the one intended for his or her type) if it were offered.
} 


\subsubsection{Stock Price Volatility (Tables 2 and 3 )}

Tables 2 and 3 present the results for a similar contracting environment, except that the sigma parameter of the stock price distribution is either 0.75 (Table 2) or 1.00 (Table 3) rather than 0.50 , so that the stock price both has a higher mean and is more volatile for a given action (i.e., higher risk and higher expected return). Comparing the pure moral hazard results with those in Table 1, we find that the principal still prefers to hire the most risk-averse agent, but there is a uniform decline in the value of the principal's objective from dealing with all three types of agents. This result follows from the agents' risk aversion and confirms the standard agency prediction that an agent's level of effort is decreasing in the volatility of the stock price (Holmstrom, 1979). In addition, the contracts for all three agents initially (in Table 2) exhibit fewer (if any) options and more shares of stock, and salary becomes a component of the contracts for the two more risk-averse types of agents. The contracts then become composed of more stock (but still no options except for the least risk-averse agent) and consist of a lower salary. The incentives provided by the optimal contracts in Tables 2 and 3 quantify this notion, in that for a given type of agent, the incentives of the optimal contract first decrease and then increase slightly. Part of the reason for the shift from options to stock as volatility increases for the two most risk-averse agents is that options become relatively more expensive for the principal as a result of the agents' risk aversion. Stock can still be used to provide incentives while also providing a payoff to the agent in low-outcome states; options do not provide such a payoff.

In the case of pure adverse selection, the agents also take uniformly lower actions than was

the case in Table 1, as manifested in a lower value of the principal's objective. The incentives that the optimal contracts provide are, however, greater for the two most risk-tolerant agents but smaller for the most risk-averse agent. In addition, the two most risk-averse agents earn 
information rents. The intuition for providing information rents to these agents is similar to the case in Table 1, where the principal is willing to offer a contract that provides rents to the agents to prevent other types from selecting this contract. Interestingly, the contract for the most risk-averse agent provides salary but also supplies information rents. This result does not typically arise in contracting models, because the principal could always offer a contract that pays less salary but is otherwise the same in terms of stock and stock-options, and the contract would still satisfy the agent's IR constraint. This result probably arises from the dual effect of both wealth effects (i.e., providing additional salary makes the agent less risk-averse and therefore more willing to take a higher action) and the prevention of other types of agents from mimicking the most risk-averse type (i.e., countervailing incentives).

When the stock price becomes more volatile, the optimal contract for Program (\#1) also yields a lower objective value for the principal (relative to Program (\#1) in Table 1) as a result of the uniformly lower actions the agents take. The composition of the contract for the most risk-averse type is similar to that in Table 1 but consists of roughly double the number of shares and stock options and still no salary. The contracts offered to the two more risk-averse agents, however, are relatively more fixed, since no options are offered and salary shows up. For each type of agent, we also observe that incentives are decreasing in volatility as we move from Tables 1 to 3 . The IR constraints of the most and least risk-averse agents bind, and the intermediate type earns increasingly higher information rents, which are required to ensure that the other two types of agents do not mimic the intermediate-type agent.

For Program (\#2), we find that it is best for the principal to hire the most risk-averse agent in Table 2. However, unlike the case in Table 1, the principal offers a different contract to this type under Program (\#2) than when there is moral hazard only. In particular, the 
contract to attract the most risk-averse agent is $\{0.283,0.011,0.000\}$ in Program (\#2) versus $\{0.076,0.020,0.000\}$, when there is only the moral hazard problem. We also observe that stock options are used only for the least risk-averse agent and that the contract for the more risk-averse agents consists of salary and stock. The difference in expected returns for the principal is $77.6 \%(=88.82 / 50-1)$ versus $85.5 \%(=92.77 / 50-1)$. When compared with the expected values in Table 1, the difference illustrates that the agency cost resulting from adverse selection is increasing in sigma.

\subsubsection{Initial Endowment (Tables 4-9)}

In Table 4, we examine a contracting environment that is similar to that in Table 1, except that each of the agents is endowed with beginning wealth of 0.50 . The results of the pure moral hazard problem are similar to those in Table 1, in that the principal still prefers to hire the most risk-averse agent, although the difference in the objective between hiring the most and least risk-averse types is less pronounced. In addition, the optimal action for each agent and the incentives provided by the optimal contract are uniformly lower than their counterparts in Table 1. This outcome obtains because the initial endowment decreases the agents' marginal utility of consumption, and the principal thus finds it relatively more costly to motivate a given action. This result can be seen graphically in Figure 1, which plots the incentives provided by the optimal contracts (around the optimal action) for a given level of beginning wealth and sigma for each agent type. Focusing on Panel A, which features the moral hazard only model, we see that the incentives surface flattens as the agents are endowed with progressively more beginning wealth.

The results of the pure adverse selection model are somewhat different from those obtained in Table 1. In particular, the optimal contracts become more convex and the incentives 
provided to the two most risk-tolerant agents increase, while the incentives provided to the most risk-averse agent decline dramatically. As in Table 1, the most risk-tolerant agent earns no information rents. Unlike in Table 1, however, the other types earn information rents that are increasing in their degree of risk aversion. Thus, the more familiar monotonic relationship between types and information rents obtains once a sufficient level of beginning wealth is introduced.

The results of Program (\#1) are similar to those in Table 1. The notable differences are that the principal's objective is lower (96.79 vs. 101.78) and the contracts provide uniformly lower incentives. This result is in part due to the nonincreasing actions induced by these contracts, since the agents have lower marginal utility as a result of their beginning wealth.

The results of Program (\#2) in Table 4 indicate that it is feasible for the principal to design a contract to hire only the two most risk-averse agents while also dissuading agents of other types. It is not feasible in this case to design a contract to hire and motivate the most risk-tolerant agent while excluding the others. Similar to Table 1, the principal prefers to hire the most risk-averse agent and does so by offering a more incentive-based contract $(\{0.000,0.001,0.018\}$ in Table 4 versus $\{0.127,0.011,0.000\}$ in Table 1$)$, which induces the agent to take the same action and provides slightly higher incentives. Interestigly, this is the same contract offered to the most risk-averse agent in the presence of moral hazard only and thus yields the same objective value for the principal, so there is no additional agency cost that arises from adding adverse selection to moral hazard in this setting in the case of Program (\#2). As a result, the principal's objective is actually slightly higher for Program (\#2) in Table 4 than in Table 1, where there are additional agency costs.

Table 7 is analogous to Table 4, except that the agents are relatively wealthier, with an initial endowment of 1.0. As discussed earlier, the moral hazard only results are dramatically 
different, since the principal's objective is now decreasing, rather than increasing, in the agents' degree of risk aversion. All three contracts consist almost entirely of stock options, and the value of the principal's objective is uniformly lower as a result of the lower actions the agents take. This result is similar to the one obtained by Kadan and Swinkels (2008) who find that it is possible for a risk-averse manager to become "too rich too soon," making him less responsive to incentives. ${ }^{21}$ The most risk-tolerant agent is also induced to take the highest action of the three types of agents, similar to the case of only moral hazard. The three contracts consist almost entirely of stock options and provide the agents with fewer options than the contracts in Table 1. The IR constraint of the least risk-averse agent continues to bind; however, the other types earn information rents that are increasing in the agents' degree of risk aversion.

Unlike in Program (\#1), there are no feasible solutions for Program (\#2) when the agents are endowed with beginning wealth of 1.0. This means that for each agent, it is not possible (feasible) for the principal to design a contract that will attract the agent (by satisfying that agent's IR constraint) and dissuading the remaining types of agents from accepting the contract (by never satisfying their IR constraints for any action). This result occurs because as the beginning wealh of the agents increases, their marginal utility of consumption becomes more similar and it becomes more difficult to screen the different types of agents.

\footnotetext{
${ }^{21}$ Since the agents in our model have power utility which exhibits wealth effects, the marginal utility of consumption is decreasing in the agent's wealth. Thus, as an agent becomes wealthier, ceteris paribus, it becomes more costly and more difficult to motivate the agent to take a personally costly action.
} 


\section{Conclusion}

This paper develops and numerically solves for the optimal contracts that emerge from an especially difficult set of agency models that include a variety of features observed in real world contracting settings. The realistic features of these models (e.g., agents with power utility and limited liability, lognormal stock price distribution, and stock options) render these models analytically intractable and therefore precludes closed-form solutions. Thus, we formulate two complementary generalized agency models that include both moral hazard and adverse selection as mathematical programs with equilibrium constraints (MPEC) and use state-of-the-art numerical algorithms to solve these complex agency models. We also develop a new measure of incentives, calculated as the change in the agent's certainty equivalent provided by the optimal contract for a change in action evaluated at the optimal action, to facilitate interpreting the optimal contracts that emerge from these programs.

In contrast to prior research (e.g., Meulbroek 2001, Hall and Murphy 2002, Dittmann and Maug 2007), we find that both restricted stock and stock options are typically part of the optimal compensation contract, especially when agents are less wealthy and less risk-averse and the firm's stock price is less volatile. There is not necessarily a monotonic relationship between (conditional) stock price volatility and the use of stock options, however, as their use is often increasing in sigma at first and then decreasing in sigma for higher values. We also find that wealth effects have an important effect on the form of the optimal contract and the resulting incentives provided by the contract. Many of the standard results that are derived from models of pure moral hazard absent wealth effects (i.e., with either CARA utility or risk-neutral agents) no longer obtain in the presence of wealth effects on the part of the agent. For example, the standard moral hazard result that the principal's objective is increasing in the risk tolerance of the agent does not obtain until the agent is endowed 
with a sufficient level of beginning wealth. In addition, when there is adverse selection, wealth effects produce an effect similar to the countervailing incentives identified by ? where less efficient agents earn information rents to prevent them from mimicking relatively more efficient agents. Finally, we find that when the principal wants to hire only a certain type of agent (i.e., Program (\#2)), the problem quickly becomes infeasible when the agents become wealthier, since their marginal utility of consumption becomes more similar. In this case, the principal is unable to design a single contract to attract and motivate one agent but exclude the others (i.e., it becomes infeasible to separate the different agent types).

Although the models developed in our analysis relate to executive compensation, they can be applied in other principal-agent settings such as supply chains and procurement (e.g., Baiman et al. 2001, Cachon 2004, Iyer et al. 2005, Zenios 2004). Two notable applications come to mind. First, much of the work in those areas involves both adverse selection and moral hazard (e.g., selecting and subsequently motivating the lowest-cost supplier). Although our settings are cast as hiring employees, they could easily be interpreted as hiring subcontractors and either Program (\#1) or Program (\#2) could be used depending on whether the principal wants to hire every subcontractor or deal exclusively with a single subcontractor, respectively. Alternatively, if the principal seeks to hire only a subset of the available subcontractors, the two models could be combined so that the principal hires the agents of the desired types but excludes the undesirable types.

Second, much of the supply chain literature involves modeling auctions, which are typically easier to solve, rather than direct revelation mechanisms such as those considered in this paper. It is well known that that direct revelation mechanisms are at least as efficient as alternative mechanism designs (e.g., auctions). Therefore, the models developed in our analysis could be used as a benchmark against which to compare the efficiency of alternative 
mechanisms.

One limitation of our analysis is that we have considered only static, single-period agency models. Extending the models to multiple periods would be particularly informative since the stated goal of most executive compensation policies are to attract, retain, and motivate key employees. Although this paper focuses on attraction (i.e., selection) and motivation (i.e., moral hazard), retention is beyond the scope of our analysis and necessarily requires a multiperiod model to examine its effect on the design of compensation contracts. For example, a multiperiod model would address the importance of commitment on the part of both the principal and the agent and would also allow for the examination of equity vesting schedules in optimal contracts. A related extension of the models developed in our analysis would be to incorporate multiple principals competing for agents (e.g., Fershtman and Judd 1987). These models would capture external labor market forces which undoubtedly affect compensation contracts that are observed in practice.

Another possible extension relates to the form of the compensation contracts. In this analysis, we constrained the contract space to consist of salary, stock, and at-the-money stock options because these three components account for the vast majority of the remuneration of high-level executives. However, with the recent changes in the accounting treatment of employee stock options, more companies are granting options that are not at-the-money (e.g., premium options with an exercise price greater than the price of the underlying stock on the grant date). A relatively straightforward extension of our model would allow the principal to endogenously set the exercise price of the stock options. This could make it relatively easier for the principal to screen agents of the various types in the presence of adverse selection as well as motivate them in the presence of moral hazard. A related extension would be to further relax the contract space to allow for more general outcome-contingent payoffs to the 
agent, as in Grossman and Hart (1983). A contract space that consists of salary, stock, and options implies that payments to the agent are non-decreasing in outcome (stock price). A more general contract space would allow the principal to offer payments that are potentially decreasing in outcome which might reduce the information rents the principal is required to pay or might elicit agents' information in a more cost-effective manner.

Another extension would be to examine the case of multidimensional asymmetric information. Although the analysis in this paper is confined to selection along a single dimension (i.e., risk aversion), in reality managers typically have superior information about multiple attributes such as their productivity, outside wealth, and their time horizon. Su and Judd (2007) demonstrate that many of the single-dimensional predictions in the optimal taxation literature no longer obtain when there are multiple dimensions of the agents' type space.

\section{References}

Araujo, A., H. Moreira. 2001. A general lagrangian approach for non-concave moral hazard problems. Journal of Mathematical Economics 35 17-39.

Armstrong, C., D. Larcker, C.-L. Su. 2007. Stock options and chief executive officer compensation. Working Paper, Stanford University.

Baiman, S., P. E. Fischer, M. V. Rajan. 2001. Performance measurement and design in supply chains. Management Science 47(1) 173-188.

Baron, D. P., R. B. Myerson. 1982. Regulating a monopolist with unknown costs. Econometrica 50 911-930.

Cachon, G. P. 2004. Supply chain coordination with contracts. S. Graves, A. G. de Kok, eds. Handbooks in Operations Research and Management Science: Supply Chain Management North Holland.

Core, J., W. Guay. 1999. The use of equity grants to manage optimal equity incentive levels. Journal of Accounting and Economics 28 151-184.

Dasgupta, P., P. Hammond, E. Maskin. 1979. The implementation of social choice rules: some general results on incentive compatibility. Review of Economic Studies 46 185-216.

Dempe, S. 2003. Annotated bibliography on bilevel programming and mathematical programs with equilibrium constraints. Optimization 52 333-359. 
Dittmann, I., E. Maug. 2007. Lower salaries and no options? On the optimal structure of executive pay. Journal of Finance 62 303-343.

Fershtman, C., K. L. Judd. 1987. Equilibrium incentives in oligopoly. American Economic Review 77 927-940.

Friend, I., M. Blume. 1975. The demand for risky assets. American Economic Review 65 901-922.

Green J., J. J. Laffont. 1977. Characterization of Satisfactory Mechanisms for the Revelation of Preferences for Public Goods. Econometrica 45 427-438.

Grossman, S. J., O. D. Hart. 1983. An analysis of the principal-agent problem. Econometrica 51 $7-45$.

Hagerty, K. M., D. R. Siegal. 1988, On the observational equivalence of managerial contracts under conditions of moral hazard and self-selection. Quarterly Journal of Economics 103 425-428.

Hall, B. J., K. J. Murphy. 2002. Stock options for undiversified executives. Journal of Accounting and Economics 33 3-42.

Harris, M., A. Raviv. 1979. Optimal incentive contracts with imperfect information. Journal of Economic Theory 20 231-259.

Hemenway, D. 1990. Propitious selection. The Quarterly Journal of Economics 105 1063-1069.

Hemenway, D. 1992. Propitious selection in insurance. Journal of Risk and Uncertainty 5 247-251.

Hemmer, T. 2004. Lessons lost in linearity: A critical assessment of the general usefulness of LEN models in compensation research. Journal of Management Accounting Research 16 149-162.

Hermalin, B. E., M. L. Katz. 1991. Moral hazard and verifiability: The effect of renegotiation in agency. Econometrica 59 1735-1753.

Holmstrom, B., P. Milgrom. 1987. Aggregation and linearity in the provision of intertemporal incentives. Econometrica 55 303-328.

iQuantic, Inc., 1999. Executive Total Direct Compensation Survey for the High Technology Industry.

Iyer, A. V., L. B. Schwarz, S. A. Zenios. 2005. A principal-agent model for product specification and production. Management Science 51(1) 106-119.

Jewitt, I. 1988. Justifying the first-order approach to the principal-agent problems. Econometrica 56 1177-1190.

Judd, K. L. and C.-L. Su. 2006. Optimal income taxation with multidimensional taxpayer types. Working paper, CMS-EMS, Kellogg School of Management, Northwestern University.

Jullien, B., B. Salanie, F. Salanie. 2003. Screening Risk-Averse Agents Under Moral Hazard: Singlecrossing and the CARA Case. Working paper.

Kadan O., J. M. Swinkels. 2008. Stock or Options? Moral Hazard, Firm Viability, and the Design of Compensation Contracts. Review of Financial Studies 21 451-482.

Kocherlakota, N. 1990. On tests of representative consumer asset pricing models. Journal of Monetary Economics 26 285-304. 
Laffont, J. J., D. Martimort. 2002. The theory of Incentives: The principal-agent relationship. Princeton University Press, Princeton, NJ.

Lambert, R. 2001. Contract theory and accounting. Journal of Accounting and Economics 32 3-87.

Lazear, E. 2000. Performance pay and productivity. American Economic Review 90 1346-1361.

Lewis, T. R., D. E. M. Sappington. 1989. Countervailing incentives in agency problems. Journal of Economic Theory 49 294-313.

Litzenberger, R., E. Ronn. 1986. A utility-based model of common stock price movements. Journal of Finance 41 67-92.

Lucas, D. 1994. Asset pricing with undiversifiable risk and short sales constraints: deeping the equity risk puzzle. Journal of Monetary Economics 34 325-342.

Luo, Z.-Q., J.-S. Pang, D. Ralph. 1996. Mathematical Programs with Equilibrium Constraints. Cambridge University Press, Cambridge, UK.

Meulbroek, L. K. 2001. The efficiency of equity-linked compensation: Understanding the full cost of awarding executive stock options. Financial Management 30 5-30.

Milgrom, P. 1987. Adverse selection without hidden information. Working Paper 8742, University of California at Berkeley.

Mirrlees, J. 1975. The theory of moral hazard and unobservable behavior: Part I. Mimeo, Nuffield College, Oxford University.

Mirrlees, J. 1999. The theory of moral hazard and unobservable behavior: Part I. Review of Economic Studies 66 3-21.

Murphy, K. J. 1999. Executive Compensation. O. Ashenfelter, D. Card, eds. Handbook of Labor Economics Vol. 3, North Holland.

Myerson, R. 1979. Incentive-compatibility and the bargaining problem. Econometrica 47 61-73.

Myerson, R. 1982. Optimal coordination mechanisms in generalized principal-agent problems. Journal of Mathematical Economics 10 67-81.

Rogerson, W. P. 1985. The first-order approach to principal-agent problems. Econometrica 53 $1357-1368$.

Su, C.-L., K. L. Judd. 2007. Computation of moral hazard problems. Working paper, CMS-EMS, Kellogg School of Management, Northwestern University.

Sung, J. 2005. Optimal contracts under adverse selection and moral hazard: a continuous-time approach. Review of Financial Studies 18(3) 1021-1073.

Zenios, S. A. 2004. Decentralized decision making in dynamic technological systems. D. Simchi-Levi, S. D. Wu, Z.-J. Shen, eds. Handbook of Supply Chain Analysis: Modeling in the E-Business Era, Springer. 

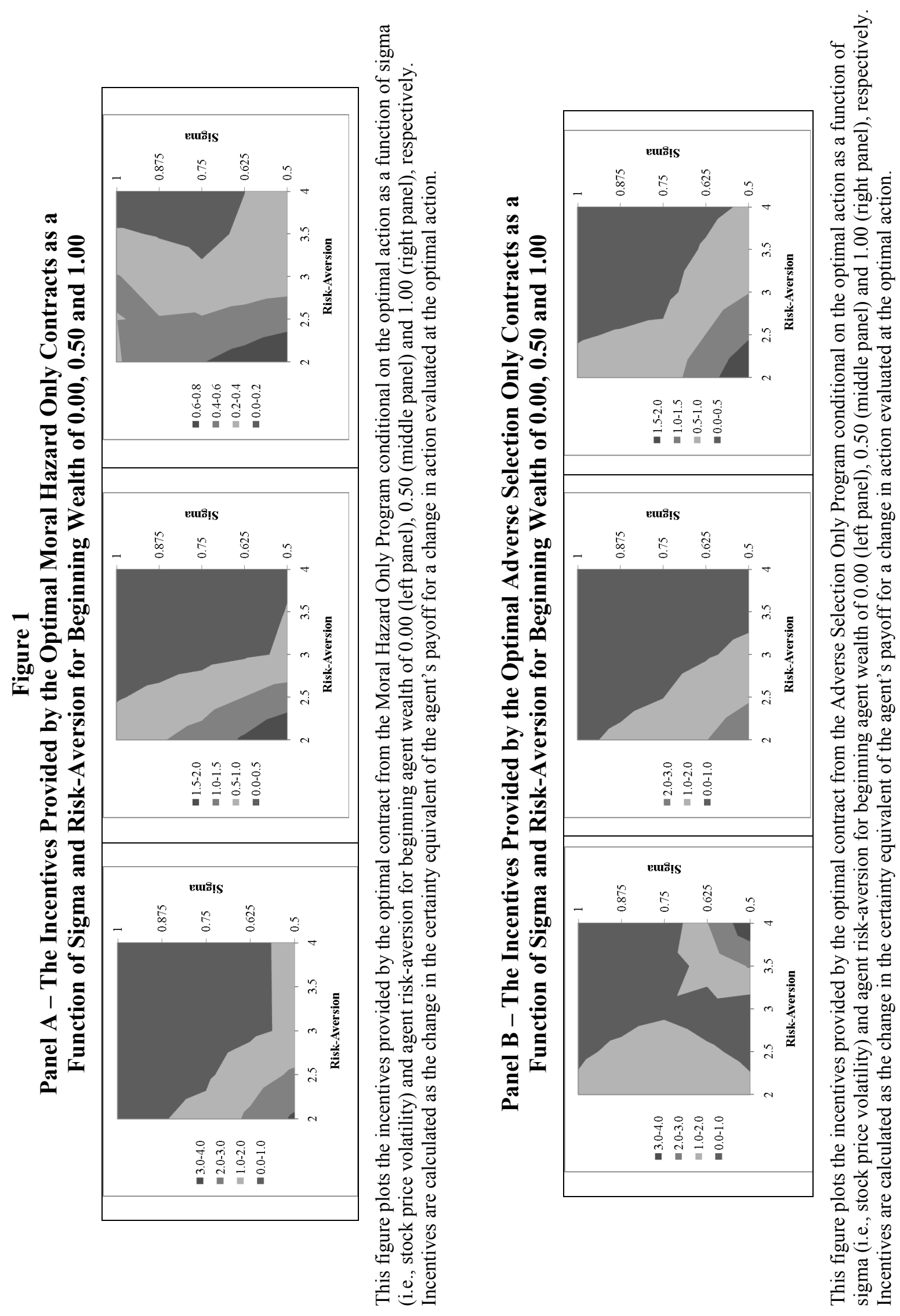


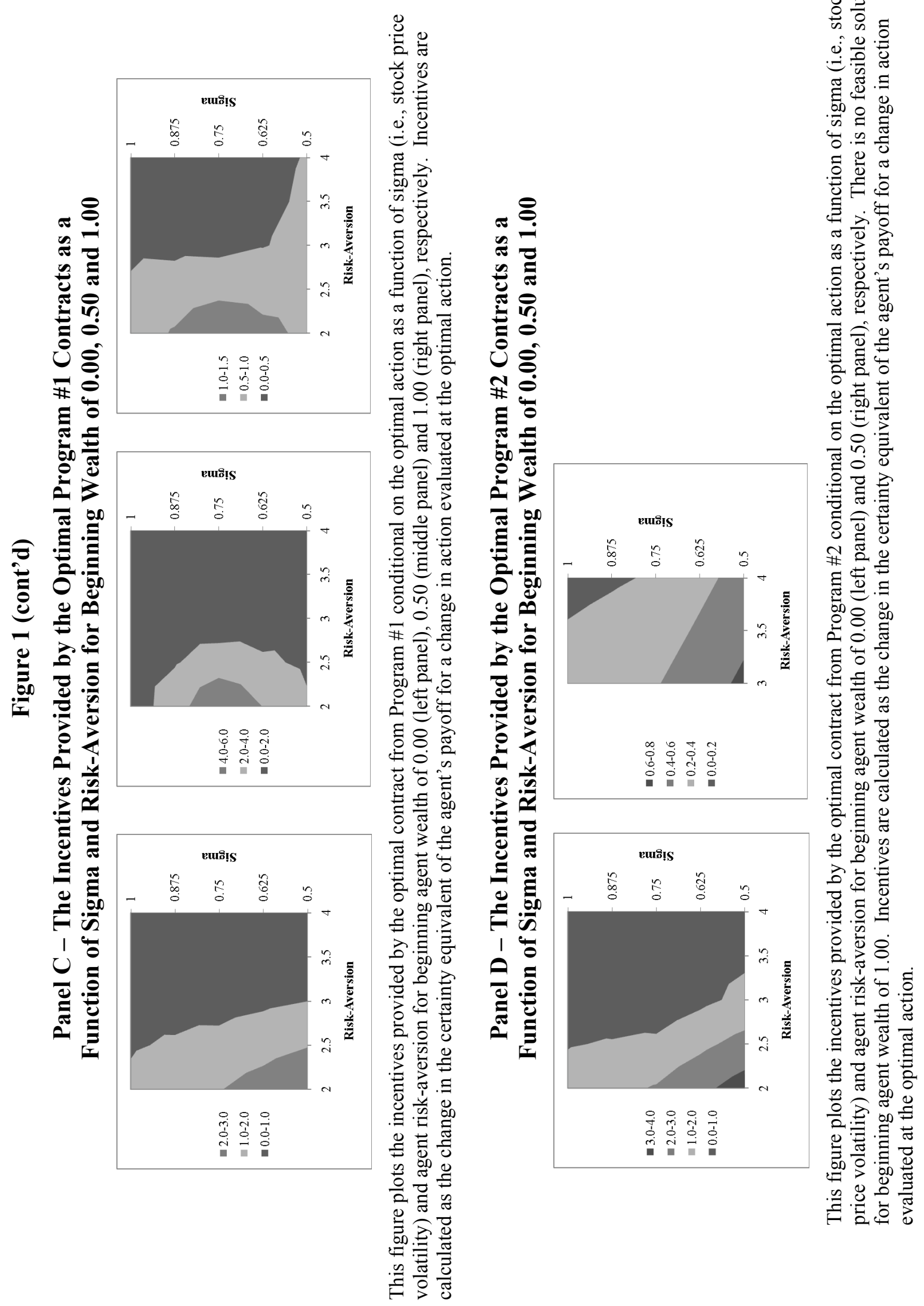



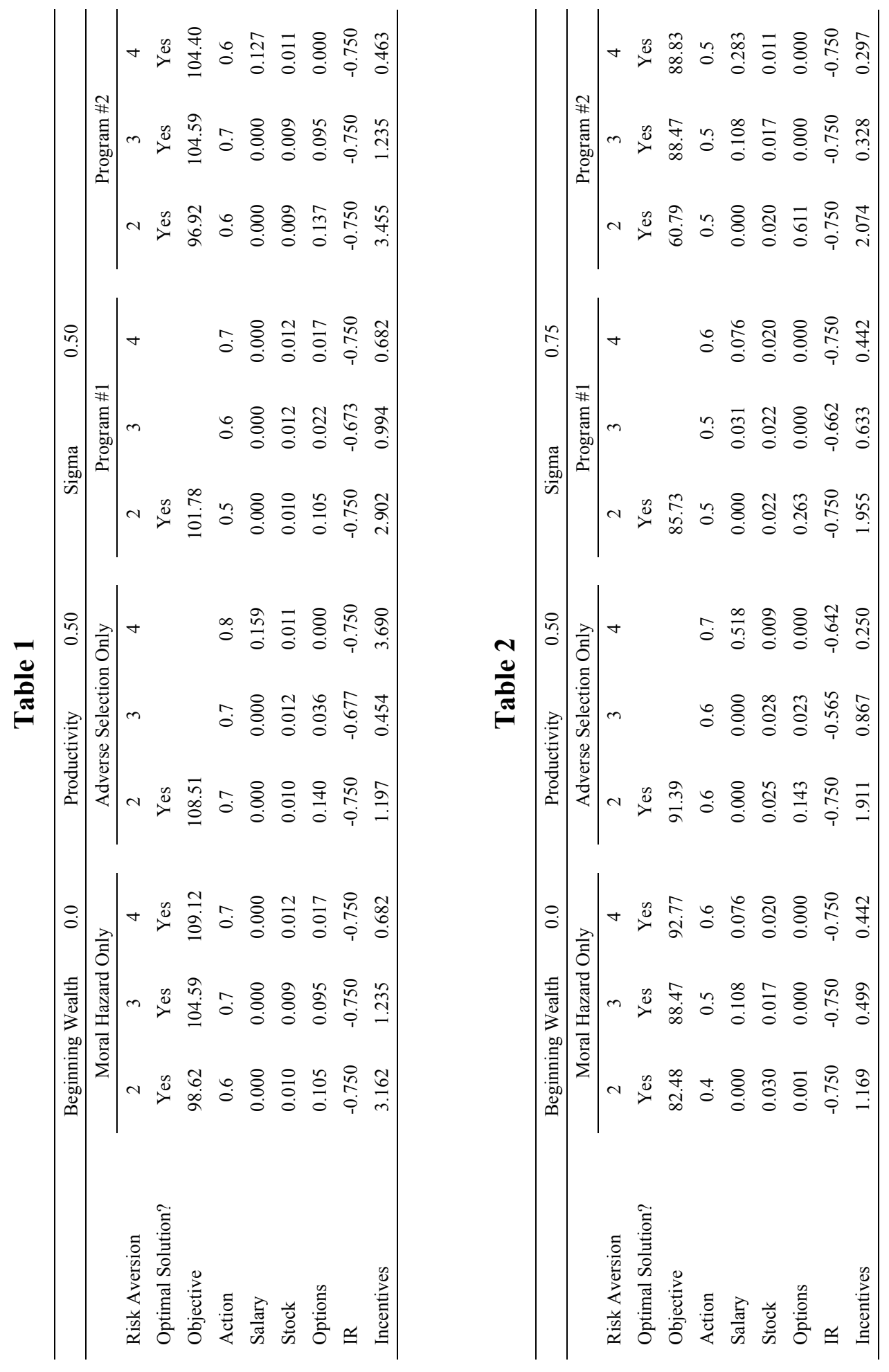

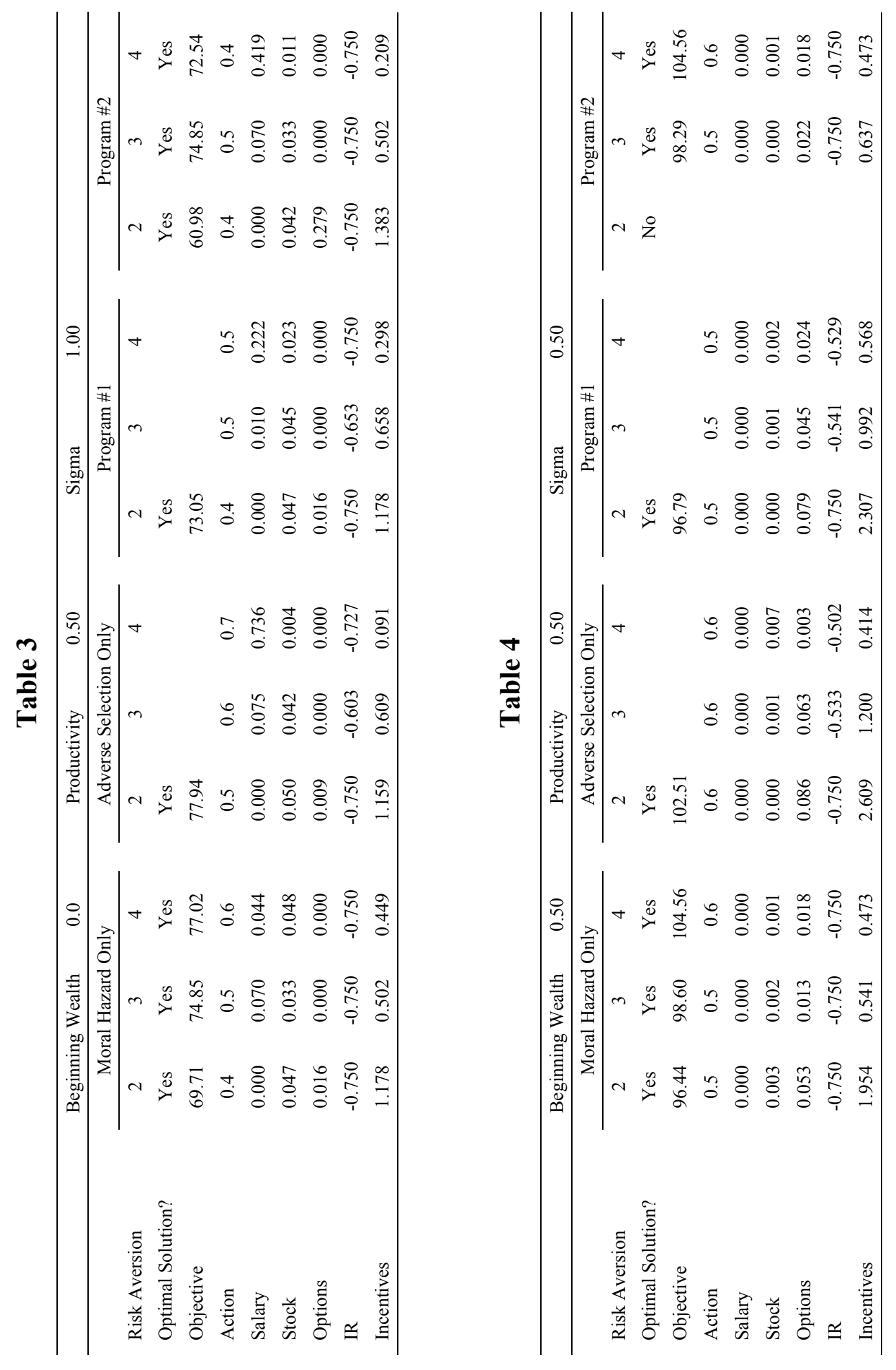

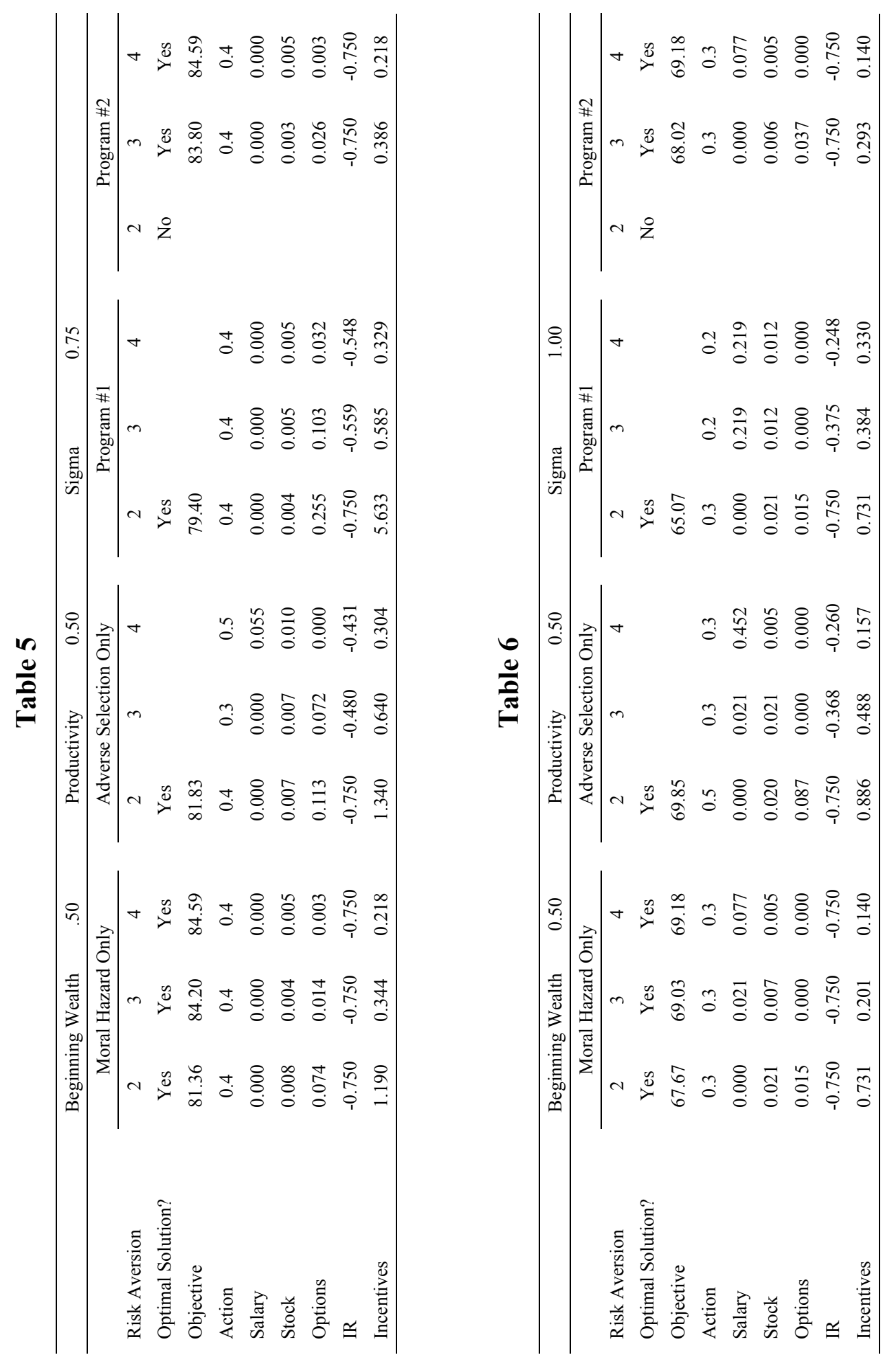




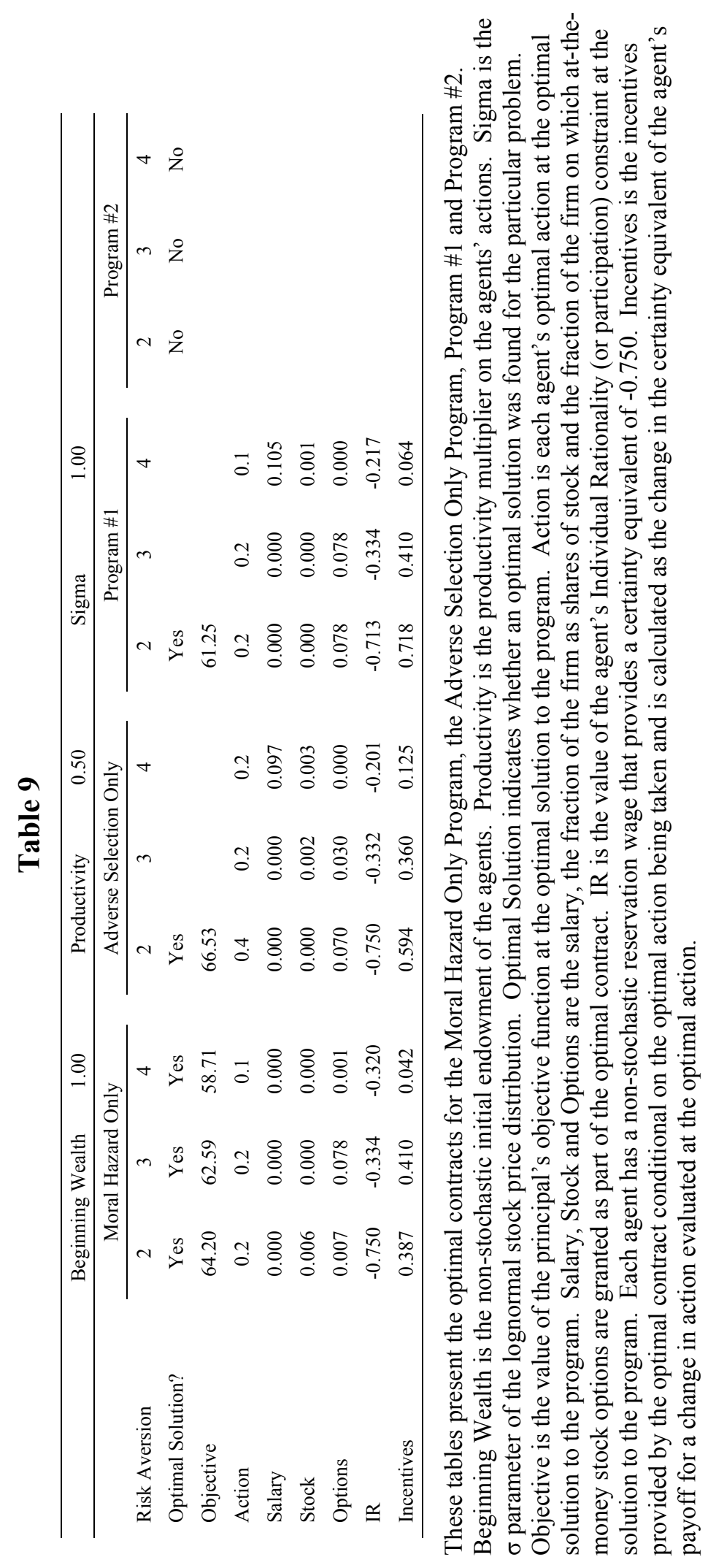

